Biomarker-assisted identification of sepsis-related acute liver impairment A frequent and deadly condition in critically ill patients

Jensen, Jens Ulrik Stæhr; Peters, Lars; Itenov, Theis S.; Bestle, Morten; Thormar, Katrin M.; Mohr, Thomas T.; Lundgren, Bettina; Grarup, Jesper; Lundgren, Jens D.

Published in:

Clinical Chemistry and Laboratory Medicine

DOI:

$10.1515 / \mathrm{cclm}-2018-1350$

Publication date:

2019

Document version

Publisher's PDF, also known as Version of record

Citation for published version (APA):

Jensen, J. U. S., Peters, L., Itenov, T. S., Bestle, M., Thormar, K. M., Mohr, T. T., Lundgren, B., Grarup, J., \& Lundgren, J. D. (2019). Biomarker-assisted identification of sepsis-related acute liver impairment: A frequent and deadly condition in critically ill patients. Clinical Chemistry and Laboratory Medicine, 57(9), 1422-1431. https://doi.org/10.1515/cclm-2018-1350 
Jens-Ulrik Stæhr Jensen*, Lars Peters, Theis S. Itenov, Morten Bestle, Katrin M. Thormar, Thomas T. Mohr, Bettina Lundgren, Jesper Grarup and Jens D. Lundgren, for the Procalcitonin And Survival Study (PASS) Groupa

\section{Biomarker-assisted identification of sepsis-related acute liver impairment: a frequent and deadly condition in critically ill patients}

https://doi.org/10.1515/cclm-2018-1350

Received December 20, 2018; accepted March 4, 2019; previously published online April 5, 2019

\begin{abstract}
Background: The prognostic impact of mild/moderate liver impairment among critically ill patients is not known. We aimed to determine whether acute liver impairment, as measured by several biomarkers, (i) is frequent, (ii) influences prognosis and (iii) to determine whether such an effect is specific for infected critically ill patients.
\end{abstract}

Methods: A biomarker and clinical cohort study based on a randomized controlled trial. All-cause mortality was

\footnotetext{
aParticipating investigators are listed in the Acknowledgements. *Corresponding author: Jens-Ulrik Stæhr Jensen, MD, PhD, CHIP \& PERSIMUNE, Department of Infectious Diseases, Rigshospitalet, University Hospital of Copenhagen and University of Copenhagen, Blegdamsvej 9, Copenhagen, Denmark, Phone: +45 35455757, Fax: +45 35455758, E-mail: jens.ulrik.jensen@regionh.dk; and Department of Internal Medicine C, Respiratory Medicine Section, Copenhagen University Hospital, Herlev-Gentofte, Denmark Lars Peters, Jesper Grarup and Jens D. Lundgren: CHIP \& PERSIMUNE, Department of Infectious Diseases, Rigshospitalet, University Hospital of Copenhagen and University of Copenhagen, Copenhagen, Denmark

Theis S. Itenov: CHIP \& PERSIMUNE, Department of Infectious Diseases, Rigshospitalet, University Hospital of Copenhagen and University of Copenhagen, Copenhagen, Denmark; and Department of Anesthesia and Intensive Care, Copenhagen University Hospital, Hillerød, Denmark Morten Bestle: Department of Anesthesia and Intensive Care, Copenhagen University Hospital, Hillerød, Denmark; and Department of Anesthesia and Intensive Care, Copenhagen University Hospital, Glostrup, Denmark

Katrin M. Thormar: Department of Anesthesia and Intensive Care, Bispebjerg Hospital, Copenhagen University Hospital, Copenhagen, Denmark; and Department of Anesthesia and Intensive Care, Copenhagen University Hospital, Gentofte, Denmark Thomas T. Mohr: Department of Anesthesia and Intensive Care, Copenhagen University Hospital, Glostrup, Denmark; and Department of Anesthesia and Intensive Care, Copenhagen University Hospital, Gentofte, Denmark

Bettina Lundgren: Diagnostic Center, Rigshospitalet and University of Copenhagen, Copenhagen, Denmark
}

the primary endpoint. Biomarkers hyaluronic acid (HA), bilirubin, albumin, alkaline phosphatase and the international normalized ratio (INR) were determined. Multivariable statistics were applied to estimate risk increase according to liver biomarker increase at baseline and the model was adjusted for age, APACHE II, severe sepsis/ septic shock vs. milder infection, chronic alcohol abuse Charlson's co-morbidity index, cancer disease, surgical or medical patient, body mass index, sex, estimated glomerular filtration rate, mechanical ventilation and the other biomarkers. Time-to-event graphs were used. The patients were critically ill patients $(n=1096)$ from nine mixed medical/surgical intensive care units without known hepatobiliary disease.

Results: HA levels differed between infected patients (median $210.8 \mathrm{ng} / \mathrm{mL}$ [IQR: 93.2-556.6]) vs. the noninfected (median $56.8 \mathrm{ng} / \mathrm{mL}$ [IQR: 31.9-116.8], p < 0.001). Serum HA quartiles 2, 3 and 4 were independent predictors of 90-day all-cause mortality for the entire population (infected and non-infected). However, the signal was driven by the infected patients (positive interaction test, no signal in non-infected patients). Among infected patients, HA quartiles corresponded directly to the 90 -day risk of dying: 1 st quartile: $57 / 192=29.7 \%$, 2nd quartile: $84 / 194=43.3 \%$, 3rd quartile: $90 / 193=46.6 \%$, 4th quartile: $101 / 192=52.3 \%$, p for trend: $<0.0001$. This finding was confirmed in adjusted analyses: hazard ratio vs. 1st quartile: 2nd quartile: 1.3 [0.9-1.8], $\mathrm{p}=0.14$, 3rd quartile: 1.5 [1.1-2.2], $\mathrm{p}=0.02$, 4th quartile: 1.9 [1.3-2.6], $\mathrm{p}<0.0001)$. High bilirubin was also an independent predictor of mortality.

Conclusions: Among infected critically ill patients, subtle liver impairment, (elevated HA and bilirubin), was associated with a progressive and highly increased risk of death for the patient; this was robust to adjustment for other predictors of mortality. HA can identify patients at high risk.

Keywords: biomarkers; infection; liver impairment; mortality. 


\section{Introduction}

Mortality in severely infected critically ill patients remains high, despite recent improvements due to increased awareness and prompt and effective treatment [1,2]. Only a small minority of critically ill septic patients have been described as having acute liver failure as defined, although a clinically relevant definition is disputed $[3,4]$. It is well-described that the liver has an important role in sepsis immunology, especially in functions like endotoxin clearance via Kuppfer cells, synthesizing immunoactive proteins such as IL-6, C-reactive protein, $\alpha$-1-antitrypsin, fibrinogen, and possibly via altering glucose homeostasis $[5,6]$. Seemingly subtle impairments in liver function (below the threshold for defined acute liver failure) could, via the corresponding immunological defect, be of clinical importance for the host response towards bacterial infection - and could have an impact on patient survival [7]. Classic biomarkers of liver injury like bilirubin, the international normalized ratio (INR) and aspartate aminotransferase (AST)/alanine aminotransferase (ALT) have several limitations in critically ill patients, including a lack of specificity for liver damage, as among others, bile duct obstruction, hemolysis, vitamin $\mathrm{K}$ antagonists, coagulopathy, hypoperfusion/hypoxemia and frequent genetic disorders may cause derangements without liver impairment [8-10]. Hyaluronic acid (HA) is a macromolecular component of the extracellular matrix - a framework for cells throughout the body [11]. Several synthases produce HA (HAS-1, HAS-2, HAS-3) [12, 13] and six genes are responsible for six hyaluronidases (HYAL1, HYAL2, HYAL3, HYAL4, PH2O/SPAM1 and HYALP1) [14] that degrade HA. The elimination of HA is primarily taken care of in the liver through receptor mediated endocytosis by the sinusoidal endothelial cells [15], and the speed of this has been shown to be highly influenced by hepatic blood flow and hepatocyte function in animal experimental sepsis [16]. In a study of porcine resuscitated septic shock, high levels of HA were seen, indicating hepatocyte dysfunction [17]. This is supported by data, observing a reduced sinusoidal HA uptake in sepsis [18], and very high levels of HA have been observed in a small study of human septic shock [19]. Recently, the turbidimetric HA assay used in the current study was validated towards the traditional EIA assay in a clinical material and in standardized test solutions [20]. The turbidimetric assay allows for routine and fairly cheap HA analysis in most hospital laboratories.

The primary objective of the current study was to determine whether subtle liver impairment, measured by abnormal HA and other liver biomarkers, is associated with mortality in a diverse population of critically ill patients without known pre-existing liver disease, and further to determine whether a possible impact on survival is specific for severely infected patients (PCT $>1.0 \mathrm{ng} / \mathrm{mL}$ vs. $\leq 1.0 \mathrm{ng} / \mathrm{mL}$ ) and to establish which liver biomarker could best describe the consequences of such a liver impairment on overall prognosis.

Secondary objectives: to determine whether there are strong correlations between the liver biomarkers and markers of endothelial dysfunction, soluble thrombomodulin and syndecan-1.

\section{Materials and methods}

\section{Study population}

This was a biobank study, based on the cohort of critically ill patients recruited into a 1200 patient multi-center randomized good clinical practice-controlled trial, the Procalcitonin And Survival Study (PASS) from 2006 to 2011. Patients were at least 18 years old and admitted to one of the participating intensive care units (ICUs). The intervention did not influence the general prognosis. For further details, please see the primary PASS publication [21].

The population for the current study consisted of patients from sites that routinely measured bilirubin and INR with enough serum to perform hyaluronic acid (HA) analysis, had measurement of bilirubin, INR and creatinine at enrolment in the PASS trial, and who did not have a verified hepato-biliary disease at recruitment (Figure 1).

\section{Biomarker measurement}

HA was measured with a particle enhanced turbidimetric immunoassay (PETIA) (Corgenix, Broomfield, CO, USA) in samples on a Hitachi 917 (Roche Diagnostics, GmbH, Mannheim, Germany) and in the dilution series on a Modular P (Roche Diagnostics GmbH, Mannheim, Germany) analyzers (test assay). We have earlier published an external validation of the assay towards the previous EIA-based standard [20]. All assays were calibrated against a standardize calibration set (Corgenix, reference 13375) and quality control with a standardized set for this purpose (Corgenix, reference 13376). Both calibration and quality control were done in accordance with the manufacturer's instructions. Reference levels of hyaluronic acid were defined as healthy blood donor HA levels [22].

\section{Outcome assessment}

The primary endpoint was "all-cause mortality within 90 days”. This was assessed by accessing the Danish National Patient Register. Follow-up was complete (100.0\%).

\section{Statistical analyses}

Comparisons of continuous data were made using Mann-Whitney $\mathrm{U}$ tests and Student's t tests where appropriate. The chi-square test 


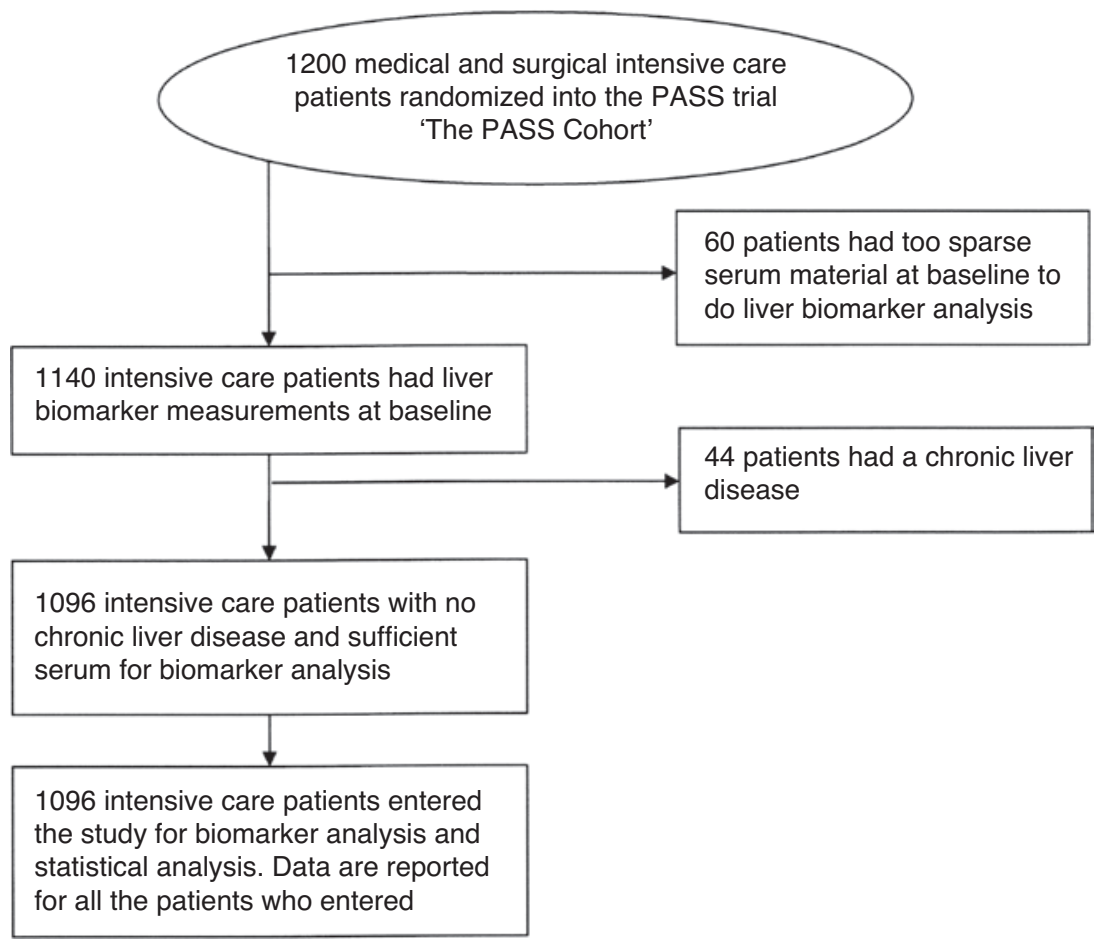

Figure 1: Flow of patients in the study.

for equal proportions was used to test categorical variables, at small numbers, using Fisher's exact test. Time-to-event analyses were performed using Kaplan-Meier plots with corresponding log rank tests and Cox proportional hazards models. Multivariable analysis of the primary endpoint was performed adjusting for known and suspected predictors of mortality (all assessed at baseline): age (per year increase), APACHE II score ( $\geq 25$ vs. $<25$ ), severe sepsis/septic shock (present vs. not), chronic alcohol abuse, Charlson's score ( $\geq 2$ vs. $<2$ ), cancer diagnosis (yes vs. no), admitted from surgical department (yes vs. no), body mass index ( $\geq 25$ vs. $<25$ ), gender (male vs. female), estimated glomerular filtration rate $\left(>60 \mathrm{~mL} / \mathrm{min} / 1.73 \mathrm{~m}^{2}\right)$ vs. $30-60 \mathrm{~mL} / \mathrm{min} / 1.73 \mathrm{~m}^{2}$ vs. $\left.<30 \mathrm{~mL} / \mathrm{min} / 1.73 \mathrm{~m}^{2}\right)$, mechanical ventilation (yes vs. no).

Pearson's correlations between liver biomarkers, endothelial biomarkers and infection biomarkers were calculated.

Statistical analyses were performed using SAS version 9.3 (SAS Institute Inc, Cary, NC, USA), version 3.0.2 (The R-project, http:// www.r-project.org/). IBM SPSS statistics 22 and Excel were used for graphs.

The study was initiated and run by doctors at our research department (CHIP, Rigshospitalet) and the participating ICUs. The data belong to the PASS study group.

\section{Ethical approval}

The study was approved by the appropriate Ethics Committee and was therefore been performed in accordance with the ethical standards laid down in the 1964 Declaration of Helsinki and its later amendments. The trial was approved by the regional Ethics Committee (KF 01272 753, KF 11297 287).

\section{Results}

\section{Patients and follow-up}

From the original randomized trial of 1200 critically ill patients, recruited at nine ICUs in Denmark, 1096 fulfilled the inclusion criteria for the current study of liver impairment among critically ill patients (Figure 1).

The baseline characteristics of the patients are available in Table 1; almost half of the patients who had PCT $>1.0 \mathrm{ng} / \mathrm{mL}$ had clinically judged septic shock; this condition was apparent in only $10.5 \%$ of those with PCT $\leq 1.0 \mathrm{ng} / \mathrm{mL}$, Table 1 .

Follow-up within 28 days after inclusion was complete $(100 \%)$ for the primary endpoint of death from any cause within 90 days.

\section{Liver biomarker levels and mortality}

HA levels were abnormally high (median $141.9 \mathrm{ng} / \mathrm{mL}$ [IQR: 60.1-416.2]) compared to healthy blood donors (median $29.1 \mathrm{ng} / \mathrm{mL}$ [IQR: 19.7-40.7]). HA levels at baseline were higher among those who were infected (median $210.8 \mathrm{ng} / \mathrm{mL}$ [IQR: 93.2-556.6]) vs. the non-infected (median 56.8 ng/mL [IQR: 31.9-116.8], p <0.001). 
Table 1: Baseline characteristics of the patients, $\mathrm{n}=1096$.

\begin{tabular}{|c|c|c|}
\hline Patient groups & $\begin{array}{r}\text { Infected (PCT }>1.0 \mathrm{ng} / \mathrm{mL}) \\
(\mathrm{n}=772)\end{array}$ & $\begin{array}{r}\text { Non-infected }(P C T \leq 1.0 \mathrm{ng} / \mathrm{mL}) \\
(\mathrm{n}=324)\end{array}$ \\
\hline \multicolumn{3}{|l|}{ General features } \\
\hline Age (years), median (IQR) & $68(60-74)$ & $68(58-77)$ \\
\hline Gender (female) & $346(44.8)$ & $158(48.8)$ \\
\hline Body mass index $\left(\mathrm{kg} / \mathrm{m}^{2}\right)$, median (IQR) & $25(22-28)$ & $25(23-28)$ \\
\hline \multicolumn{3}{|l|}{ Acute illness } \\
\hline APACHE II Score, median (IQR) & $20(14-26)$ & $15(10-20)$ \\
\hline Temperature $\left({ }^{\circ} \mathrm{C}\right)$, median (IQR) & $37.4(36.5-38.2)$ & $37.0(36.2-37.7)$ \\
\hline Glasgow Coma scale, median (IQR) & $15(15-15)$ & $15(15-15)$ \\
\hline Mechanical ventilation & $525(68.0)$ & $204(63.0)$ \\
\hline Surgical department before intensive care & $231(30.0)$ & $75(23.2)$ \\
\hline Septic shock, n (\%) & $368(47.7)$ & $34(10.5)$ \\
\hline \multicolumn{3}{|l|}{ Chronic health } \\
\hline Chronic alcohol abuse, n (\%) & $52(6.7)$ & $23(7.1)$ \\
\hline Cancer, n (\%) & $102(13.2)$ & $29(9.0)$ \\
\hline Chronic obstructive lung disease, $n(\%)$ & $124(16.1)$ & $108(33.3)$ \\
\hline \multicolumn{3}{|l|}{ Charlson's score category, n (\%) } \\
\hline 0 & $304(39.4)$ & $73(22.5)$ \\
\hline 1 & $222(28.8)$ & $135(41.7)$ \\
\hline 2 & $163(21.1)$ & $82(25.3)$ \\
\hline 3 & $54(7.0)$ & $26(8.0)$ \\
\hline 4 & $19(2.5)$ & $6(1.9)$ \\
\hline 5 & $2(0.3)$ & $1(0.3)$ \\
\hline 6 & $7(0.9)$ & $1(0.3)$ \\
\hline 7 & $1(0.1)$ & $0(0.0)$ \\
\hline \multicolumn{3}{|l|}{ Markers of hepatic and renal function } \\
\hline HA, ng/mL, median (IQR) & $211(93-557)$ & $57(32-117)$ \\
\hline INR, median (IQR) & $1.4(1.2-1.6)$ & $1.1(1.0-1.3)$ \\
\hline Albumin $(\mu \mathrm{mol} / \mathrm{L})$, median (IQR) & $313(227-405)$ & $421(316-508)$ \\
\hline Bilirubin ( $\mu \mathrm{mol} / \mathrm{L})$, median (IQR) & $10(6-18)$ & $7(4-12)$ \\
\hline Alkaline phosphatase (U/L), median (IQR) & $84(55-123)$ & $83(61-116)$ \\
\hline MELD, median (IQR) & $16(11-21)$ & $9(7-13)$ \\
\hline Creatinine $(\mu \mathrm{mol} / \mathrm{L})$, median $(\mathrm{IQR})$ & $143(91-231)$ & $85(62-116)$ \\
\hline
\end{tabular}

$I Q R$, interquartile range; HA, hyaluronic acid; INR, international normalized ratio; MELD, model for end-stage liver disease. Baseline was defined as the first calendar date the patient was included into the study and this was maximum $24 \mathrm{~h}$ later than intensive care admission.

HA levels differed most; to a lesser extent INR, bilirubin and albumin. Alkaline phosphatase did not differ between infected and non-infected patients, except on day 2, Supplementary digital Table 1.

As expected, most of the tested liver biomarkers were correlated to each other (Pearson's correlation coefficients ranging between 0.15 and 0.33 [numeric]), Figure 2. Interestingly, HA, bilirubin and the model for end-stage liver disease (MELD) score were all moderatehighly correlated to the endothelial markers (sTM and syndecan-1), Figure 2.

HA levels tended to be higher on day 3 among those patients initially randomized to high exposure to broadspectrum antibiotics, however, this was not a significant difference, $p=0.10$, Wilcoxon signed rank test.
In infected ICU patients, HA serum level quartiles corresponded directly and stepwise to the 90-day risk of dying: 1st quartile: $57 / 192=29.7 \%$, 2nd quartile: $84 / 194=43.3 \%$, 3rd quartile: $90 / 193=46.6 \%$, 4th quartile: $101 / 192=52.3 \%$, p for trend: $<0.0001$. The cumulative hazard for all-cause mortality, corresponding to liver biomarker levels, is shown in Figure 3; for HA, bilirubin and MELD, there was a highly significant increase in mortality risk according to biomarker levels. HA seemed to have the clearest and most direct correspondence between serum levels and mortality risk, reaching excessive high risk in 3rd and 4th quartiles.

To control for known and possible confounders, we built a Cox proportional hazards model for each biomarker, including predictors of mortality defined in the literature 

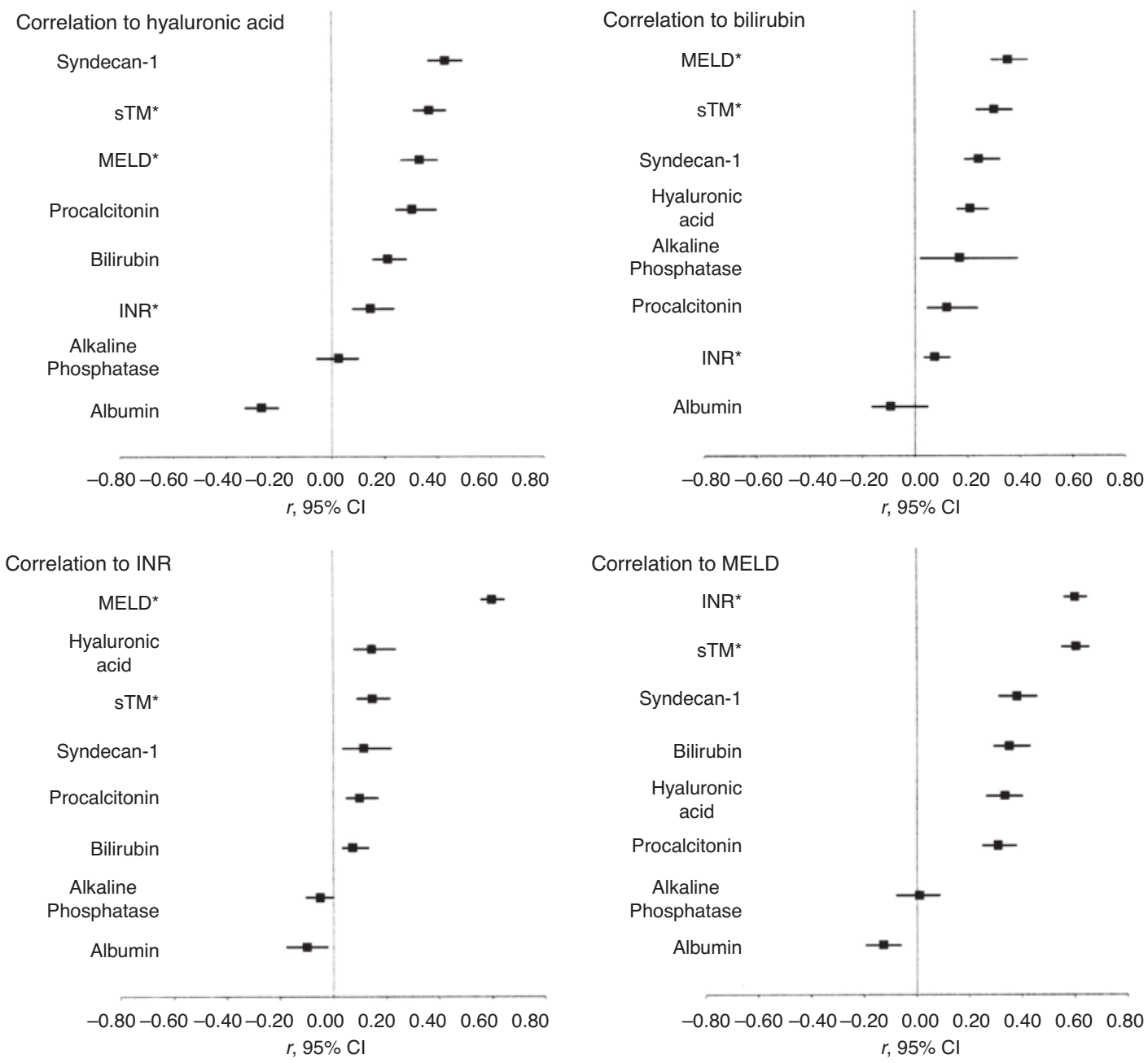

Figure 2: Correlations between the liver markers and the endothelial damage markers.

MELD, model for end-stage liver disease; sTM, soluble thrombomodulin; INR, international normalized ratio.

[23, 24] and based on our own previous data [25]. Elevated $\mathrm{HA}$ and bilirubin were associated with an increased risk of death in multivariable analysis; in unadjusted analysis, all the liver biomarkers predicted mortality, Table 2.

To find out if liver impairment carries a high mortality risk in critically ill patients as such, and if this risk is linked to the liver's function in the immune defense towards infection, we did an interaction analysis, testing the interaction between PCT below or above $1.0 \mathrm{ng} / \mathrm{mL}$ vs. HA levels in quartiles towards all-cause 90-day mortality. We found an interaction, $p=0.04$. Finally, applying the Cox regression model to all the non-infected critically ill patients, no increased risk was detected in patients with abnormal liver function tests, $\mathrm{p}$-value range: $0.18-0.93$.

Testing liver biomarker quartiles for HA, bilirubin, INR and MELD, while adjusting for each other in the infected population, we found a highly significant increased risk of death for every quartile increase in hazard ratio (HA [every quartile increase]: 1.2 [95\% CI: 1.1-1.3], $\mathrm{p}=0.005$ ), whereas this was not the case for the other liver biomarkers (p-values ranging $0.12-0.88$ ).

The ability of APACHE II to predict 90-day mortality was increased from an AUC of 0.625-0.650 when the HA was added. We estimated the net reclassification improvement (NRI) and the integrated discrimination improvement (IDI) by using two logistic regression models for APACHE II (classic) and for APACHE II (enriched with HA) towards the 90-day mortality. The NRI was 0.27 ([95\% CI: $\left.0.15-0.38], \mathrm{p}=5.1 \times 10^{-6}\right)$ and the IDI was 0.0225 (95\% CI: $\left.0.013-0.032), p=2.4 \times 10^{-6}\right)$.

In the model of the infected patients, to explore whether high exposure of broad-spectrum antibiotics, as administered in the intervention arm of the PASS trial, interacted with the prediction estimate of the hyaluronic acid, we tested whether the randomization group interacted with the hyaluronic acid quartiles in the prediction estimate of the Cox model; this was not the case, $p$-value for interaction 0.24 . 

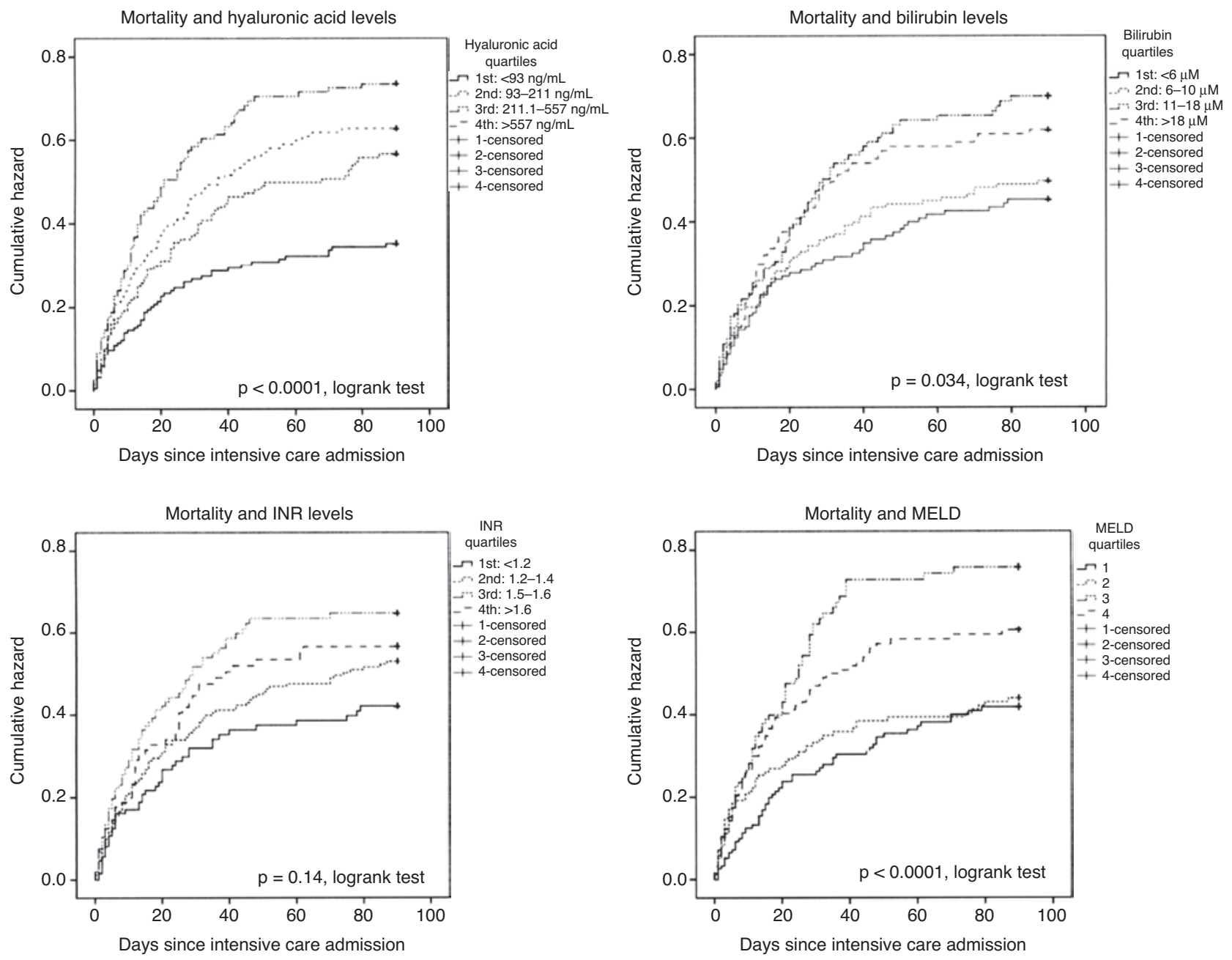

Figure 3: Mortality and liver biomarker quartiles.

INR, international normalized ratio; MELD, model for end-stage liver disease.

\section{Discussion}

In a broad population of infected critically ill patients, subtle changes in liver function added a striking high and independent risk of dying within 3 months. This was confirmed by analyzing several different liver biomarkers. HA seemed to capture this subtle liver function impairment most comprehensively.

It is unknown whether such a subtle liver impairment in general carries a mortality risk increase in critically ill patients, or whether this effect is linked to the liver's role in host defense towards infections. To further substantiate this, we compared the impact of liver impairment in patients who did not suffer from severe infection $(\mathrm{PCT}<1.0 \mathrm{ng} / \mathrm{mL}$ ) with the impact of liver impairment among patients with more severe infection (PCT $\geq 1.0 \mathrm{ng} / \mathrm{mL}$ ). The results were clear; when exploring mortality, we found a strong interaction between severe infection and liver impairment $(\mathrm{p}=0.04)$. When subsequently analyzing the subgroup of patients, who did not have severe infection (PCT $<1.0 \mathrm{ng} / \mathrm{mL}$ ), no liver variable carried an increased mortality risk.

Compared to other types of organ failure, like acute respiratory failure, acute kidney failure and acute heart failure, not much attention has been placed on liver dysfunction in sepsis and critical illness. Little is known about the mortality attributed to liver impairment in critically ill patients, and whether this is linked to infection and whether biomarkers can detect this liver impairment early after admission to the ICU $[7,26]$. In sepsis patients, the prevalence of liver dysfunction is not certain as estimates range from $1 \%$ to $26 \%$ in larger patient materials $[3,7]$; however, it has been concluded that the lack of reliable diagnostic tools, preclude the early detection of liver impairment in sepsis. We found that nearly $85 \%$ of the ICU patients have abnormally high HA levels 


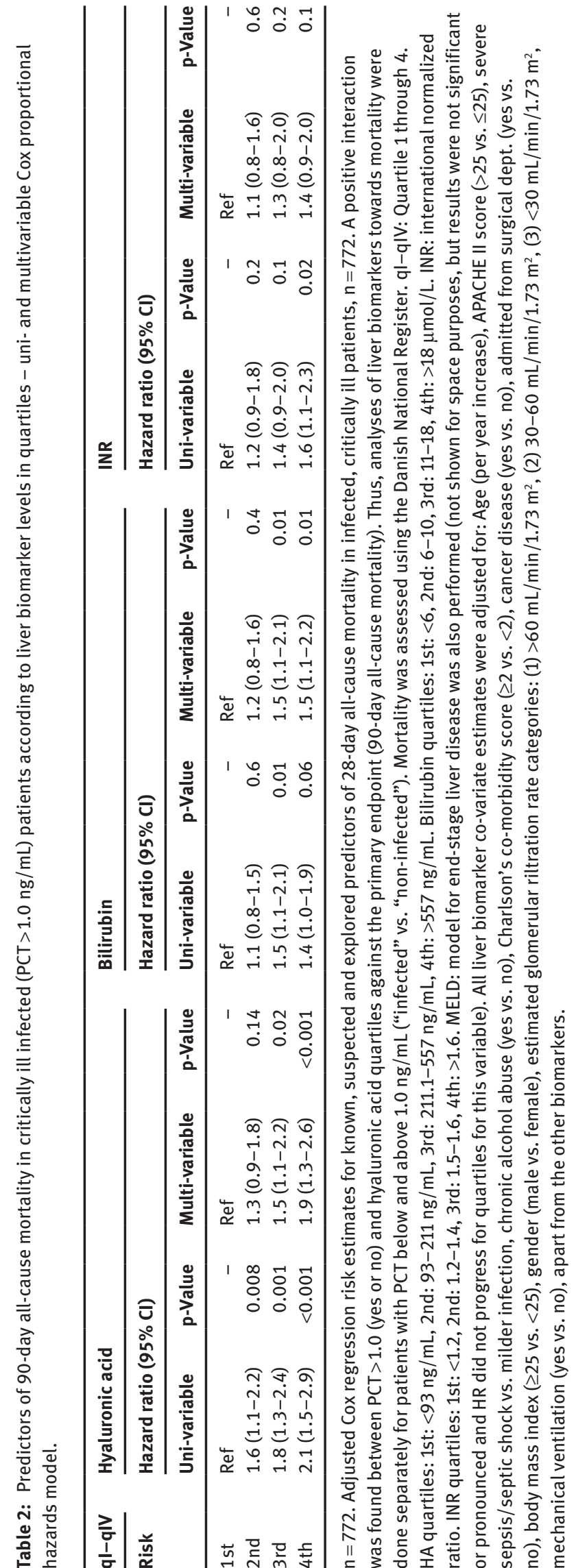

compared to levels in blood donors. Fifty percent of the infected critically ill patients with the highest HA (3rd and 4th quartiles) have significantly increased 90-day mortality; a finding robust for adjustment for a range of known and suspected predictors of mortality. Additionally, when entering all the tested liver biomarkers into a multivariable analysis, thus adjusting for each other, only HA and bilirubin predicted mortality. Thus, abnormal HA levels are frequent in critically ill patients. In the infected critically ill patients at least $50 \%$ of those who have HA levels at baseline above the median, have severely compromised prognosis compared to those with HA in the lowest quartile.

This strongly questions whether the currently used definitions of liver impairment are relevant for septic critically ill patients [3,4] and should increase awareness towards liver-function preserving interventions which are urgently needed in a multifaceted sepsis management approach. Using the SOFA score hepatic component (bilirubin-based), the incidence of hepatic dysfunction was estimated in larger studies to be $36-47 \%$, which approaches our observations, however, the impact on mortality has not been systematically explored in these studies [27, 28].

In sepsis, the role of the liver is not fully understood; however, it is clear that the liver has important functions in the host response towards bacterial infection. The liver acts as a scavenger for bacteria and bacterial products $[29,30]$. An active crosstalk takes place between blood cells and different liver cells like hepatocytes, Kupffer cells and sinusoidal endothelial cells to regulate the proand anti-inflammatory response in sepsis. Hepatic lipoprotein clearance in sepsis seems to be highly dependent on Proprotein convertase subtilisin/kexin type 9 (PCSK9), as inhibition of this system leads to lower bacterial loads, a lower degree of liver and kidney pathology and lower IL-10 and myeloperoxidase levels [31]. Additionally, profound changes in coagulation take place in sepsis via antithrombin and protein $\mathrm{C}$ downregulation resulting in an early pro-coagulant state; the magnitude of the latter possibly being influenced by the degree of liver impairment during the septic insult [32].

Based on our results it seems plausible that severe dysregulation of these hepatic systems, involved in the response to bacterial infection, can affect the course of the infection and thereby the mortality risk.

Most of the liver biomarkers, and especially HA, were correlated to the biomarkers of endothelial function (sTM and syndecan-1), indicating a link to the endothelial damage often present in sepsis. It was beyond the scope of the current study to conclude whether this link 
is primarily via hepatic sinusoid endothelial cells, or to a higher extent, via non-hepatic endothelium. However, as this correlation between HA and endothelial markers is not very strong, it seems there must be other important host defense functions that are compromised in sepsisrelated hepatic impairment.

Interestingly, while HA levels were closely linked to prognosis among patients with severe infection, increased levels of HA were not associated with prognosis among patients without severe infection $(\mathrm{p}$ for interaction $=0.04$. This discrepancy strongly suggests that the role of the liver is pivotal in sepsis survival, and that a beneficial response to bacterial infection is dependent on the degree of sepsisrelated liver damage.

\section{Strengths and limitations}

The current study is a biobank study with a linked cohort, carrying the built-in limitations of cohort studies compared to randomized trials. As some departments in the trial did not routinely measure INR, more than 200 patients had missing values on this parameter. In 75 patients, there was an insufficient volume of serum, and we cannot expand our conclusions to the patients where biomarkers were not measured. The strengths of the study are (i) the relatively high sample size - the sample size of 1096 is to the best of our knowledge the largest total number of critically ill patients available with a suitable biobank for hepatic biomarker analysis (ii) the complete follow-up for the endpoints due to good clinical practice-based clinical monitoring and follow-up based on the Danish hospital registers, and (iii) the completeness of data on a wide variety of clinical, biochemical and microbiological data in these patients. Additionally, we were able to identify patients with verified chronic liver disease, and by excluding these the influence of chronic liver failure is less likely to influence the results.

\section{Conclusions}

In summary, sepsis-related acute liver impairment (SALI) is present early in the ICU admission, is frequent, and is associated with a high mortality rate. In not severely infected patients, liver impairment did not seem to influence mortality. HA and bilirubin could identify patients at risk, HA seems to capture this excess risk for more patients. Mortality estimates were progressively higher for every quartile HA increased.
In the understanding and management of severe bacterial infections, more attention is needed on hepatic function and how the liver host response is preserved in sepsis. Future trial targets could aim at preserving Kupffer cells, hepatocytes and sinusoidal endothelial cell early in sepsis. Monitoring of septic ICU patients with HA on a daily basis could be implemented as a way to differentiate infection treatment response, both regarding hepatic impairment and overall prognosis.

Acknowledgments: The authors wish to thank: The Procalcitonin And Survival Study Data and Safety Monitoring Board for the primary study: H. Masur (Chair), J. Chastre, H. Schønheyder, C. Pedersen and the Procalcitonin And Survival Study Group (PASS-group): M. Steensen; K. Thornberg; D. Strange; A. Ø. Lauritsen; P. Søe-Jensen; N. Reiter; N.E. Drenck; P. Fjeldborg; Z. Fox; J. Kjær; D. Kristensen; M. B. Rasmussen; C. S.v. Hallas; M. Zacho; C. Østergaard; P.L. Petersen; S. Hougaard; T. Mantoni; L. Nebrich; A. Bendtsen; L.H. Andersen; F. Bærentzen; Andreas Eversbusch; B. Bømler; R. Martusevicius; T. Nielsen; P.M. Bådstøløkken; U. Grevstad; P. Hallas; A. Lindhardt; T. Galle; K. Graeser; E. Hohwu-Christensen; P. Gregersen; L.M. Pedersen; L.C. Hallengreen; I. Rye; J. Cordtz; K.R. Madsen; P.R.C. Kirkegaard; L. Findsen; L.H. Nielsen; D.H. Pedersen; J.H. Andersen; C. Albrechtsen; A. Jacobsen; T. Jansen; A.G. Jensen; H.H. Jørgensen; M. Vazin; L. Lipsius; M. Skielboe; B. Thage; C. Thoft; M. Uldbjerg; E. Anderlo; M. Engsig; F. Hani; R.B. Jacobsen; L. Mulla; U. Skram; T. Waldau; T. Faber; B. Andersen; I. Gillesberg; A. Christensen; C. Hartmann; R. Albret; D.S. Dinesen; K. Gani; M. Ibsen; J.A. Petersen; P. Carl; E. Gade; D. Solevad; C. Heiring; M. Jørgensen; K. Ekelund; A. Afshari; N. Hammer; M. Bitsch; J.S. Hansen; C. Wamberg; T.D. Clausen; R. Winkel; J. Huusom; D.L. Buck; U. Grevstad; K. Lenz; P. Mellado; H. Karacan; J. Hidestål; J. Høgagard; J. Højbjerg; J. Højlund; S. Hestad; M. Østergaard; N. Wesche; S.A. Nielsen; H. Christensen; H. Blom; C.H. Jensen; K. Nielsen; N.G. Holler; C.D. Rossau; M. Glæemose; M.B. Wranér; C.B. Thomsen; B. Rasmussen; C. Lund-Rasmussen; B. Bech; K. Bjerregaard; L. Spliid, L.L.W. Nielsen; K.M. Larsen; M. Goldinger; D. Illum; C. Jessen; A. Christiansen; A. Berg; T. Elkmann; J.A.K. Pedersen; M. Simonsen; H. Joensen ${ }^{\dagger}$ (Deceased); H. Alstrøm; C. Svane; A. Engquist.

Data availability: The clinical and biochemical data used to support the findings of this study are restricted by the Ethics Board for the Capital Region of Denmark, KF 01-272-753, KF 11297287 and the Danish data protection law, in order to protect patient privacy. Data are available from the corresponding author for researchers who meet the criteria for access to confidential data. External 
researchers can apply the Ethics Board of the Capital Region of Denmark for access. The authors will guide and help with such an application.

Author contributions: Contributors: JUJ, TSI and JDL had full access to all of the data in the study and take responsibility for the integrity of the data and the accuracy of the data analysis. All authors contributed substantially to conception and design, or acquisition of data, or analysis and interpretation of data. JUJ and JDL drafted the article. Statistical analysis: JUJ, TSI, JDL. Obtained funding: JUJ, JDL, BL. Administrative, technical, or material support: All authors. All other authors revised it critically for important intellectual content. All authors gave final approval of the version to be published.

Research funding: This work was supported by the Danish National Research Foundation [Funder Id: http://dx.doi. org/10.13039/501100001732, Grant Number: DNRF126] (CHIP \& PERSIMUNE), The Lundbeck Foundation, and the Idella Foundation.

Employment or leadership: None declared.

Honorarium: None declared.

Competing interests: All authors have completed the Unified Competing Interest form at http://www.icmje.org/ coi_disclosure.pdf and declare: Dr. Jensen reports travelling to medical congress in 2016 with Roche Pharmaceutical and 2017 with Boehringer-Ingelheim. Other than this, Dr. Jensen has no conflicts of interest. Our institution received reagents for HA from Corgenix Inc, CO, USA. No financial funding was received from any company. All authors declare: no financial relationships with any organizations that might have an interest in the submitted work in the previous 3 years; no other relationships or activities that could appear to have influenced the submitted work.

\section{References}

1. Angus DC, Barnato AE, Bell D, Bellomo R, Chong CR, Coats TJ, et al. A systematic review and meta-analysis of early goaldirected therapy for septic shock: the ARISE, ProCESS and ProMISe Investigators. Intensive Care Med 2015;41:1549-60.

2. Caironi P, Tognoni G, Masson S, Fumagalli R, Pesenti A, Romero $M$, et al. Albumin replacement in patients with severe sepsis or septic shock. N Engl J Med 2014;370:1412-21.

3. Angus DC, Linde-Zwirble WT, Lidicker J, Clermont G, Carcillo J, Pinsky MR. Epidemiology of severe sepsis in the United States: analysis of incidence, outcome, and associated costs of care. Crit Care Med 2001;29:1303-10.

4. Bakker J, Grover R, McLuckie A, Holzapfel L, Andersson J, Lodato R, et al. Administration of the nitric oxide synthase inhibitor NG-methyl-L-arginine hydrochloride (546C88) by intravenous infusion for up to 72 hours can promote the resolution of shock in patients with severe sepsis: results of a randomized, double-blind, placebo-controlled multicenter study (study no. 144-002). Crit Care Med 2004;32:1-12.

5. Casteleijn E, Kuiper J, Van Rooij HC, Kamps JA, Koster JF, Van Berkel TJ. Endotoxin stimulates glycogenolysis in the liver by means of intercellular communication. J Biol Chem 1988;263:6953-5.

6. Wallington J, Ning J, Titheradge MA. The control of hepatic glycogen metabolism in an in vitro model of sepsis. Mol Cell Biochem 2008;308:183-92.

7. Nesseler N, Launey Y, Aninat C, White J, Corlu A, Pieper K, et al. Liver dysfunction is associated with long-term mortality in septic shock. Am J Respir Crit Care Med 2016;193:335-7.

8. Thomson SJ, Cowan ML, Johnston I, Musa S, Grounds M, Rahman TM. 'Liver function tests' on the intensive care unit: a prospective, observational study. Intensive Care Med 2009;35:1406-11.

9. Jenniskens M, Langouche L, Vanwijngaerden YM, Mesotten D, Van den Berghe G. Cholestatic liver (dys)function during sepsis and other critical illnesses. Intensive Care Med 2016;42:16-27.

10. Sieg A, Stiehl A, Raedsch R, Ullrich D, Messmer B, Kommerell B. Gilbert's syndrome: diagnosis by typical serum bilirubin pattern. Clin Chim Acta 1986;154:41-7.

11. Laurent TC, Fraser JR. Hyaluronan. FASEB J 1992;6:2397-404.

12. Itano N, Kimata K. Mammalian hyaluronan synthases. IUBMB Life 2002;54:195-9.

13. Weigel PH, Hascall VC, Tammi M. Hyaluronan synthases. J Biol Chem 1997;272:13997-4000.

14. Csoka AB, Frost GI, Stern R. The six hyaluronidase-like genes in the human and mouse genomes. Matrix Biol 2001;20:499-508.

15. Henriksen JH, Bentsen KD, Laurent TC. Splanchnic and renal extraction of circulating hyaluronan in patients with alcoholic liver disease. J Hepatol 1988;6:158-66.

16. Lebel L. Turnover of circulating hyaluronan. Studies in man and experimental animal (dissertation). Acta Univ Ups 1989;217:1-54.

17. Berg S, Jansson I, Hesselvik FJ, Laurent TC, Lennquist S, Walther S. Hyaluronan: relationship to hemodynamics and survival in porcine injury and sepsis. Crit Care Med 1992;20:1315-21.

18. Alston-Smith JP, Fraser JR, Laurent TC. Effects of endotoxin in hepatic endocytosis of hyaluronan BOOK: hepatic endocytosis of lipids and proteins. München, Germany: Zuckschwerdt, 1992.

19. Berg S, Brodin B, Hesselvik F, Laurent TC, Maller R. Elevated levels of plasma hyaluronan in septicaemia. Scand J Clin Lab Invest 1988;48:727-32.

20. Itenov TS, Kirkby NS, Bestle MH, Nilsson AC, Erlandsen EJ, Peters L, et al. Hyaluronic acid assays: turbidimetric or enzymebased immune assay? A method comparison study. J Clin Lab Anal 2016;30:524-8.

21. Jensen JU, Hein L, Lundgren B, Bestle MH, Mohr TT, Andersen $\mathrm{MH}$, et al. Procalcitonin-guided interventions against infections to increase early appropriate antibiotics and improve survival in the intensive care unit: a randomized trial. Crit Care Med 2011;39:2048-58.

22. Majeed M, McQueen F, Yeoman S, McLean L. Relationship between serum hyaluronic acid level and disease activity in early rheumatoid arthritis. Ann Rheum Dis 2004;63:1166-8.

23. Williams JM, Greenslade JH, Chu K, Brown AF, Lipman J. Severity scores in emergency department patients with presumed infection: a prospective validation study. Crit Care Med 2016;44:539-47.

24. White LE, Hassoun HT, Bihorac A, Moore L), Sailors RM, McKinley $\mathrm{BA}$, et al. Acute kidney injury is surprisingly common and a powerful predictor of mortality in surgical sepsis. J Trauma Acute Care Surg 2013;75:432-8. 
25. Jensen JS, Itenov TS, Thormar KM, Hein L, Mohr TT, Andersen $\mathrm{MH}$, et al. Prediction of non-recovery from ventilator-demanding acute respiratory failure, ARDS and death using lung damage biomarkers: data from a 1200-patient critical care randomized trial. Ann Intensive Care 2016;6:114.

26. Nesseler N, Launey Y, Aninat C, Morel F, Malledant Y, Seguin P. Clinical review: the liver in sepsis. Crit Care 2012;16:235.

27. Vincent JL, Angus DC, Artigas A, Kalil A, Basson BR, Jamal HH, et al. Effects of drotrecogin alfa (activated) on organ dysfunction in the PROWESS trial. Crit Care Med 2003;31:834-40.

28. Brun-Buisson C, Meshaka P, Pinton P, Vallet B, Group ES. EPISEPSIS: a reappraisal of the epidemiology and outcome of severe sepsis in French intensive care units. Intensive Care Med 2004;30:580-8.

29. van der Laan LJ, Dopp EA, Haworth R, Pikkarainen T, Kangas $\mathrm{M}$, Elomaa $\mathrm{O}$, et al. Regulation and functional involvement of macrophage scavenger receptor MARCO in clearance of bacteria in vivo. J Immunol 1999;162:939-47.

30. Guo L, Zheng Z, Ai J, Huang B, Li XA. Hepatic scavenger receptor BI protects against polymicrobial-induced sepsis through promoting LPS clearance in mice. J Biol Chem 2014;289:14666-73.

31. Dwivedi DJ, Grin PM, Khan M, Prat A, Zhou J, Fox-Robichaud AE, et al. Differential expression of PCSK9 modulates infection, inflammation and coagulation in a murine model of sepsis. Shock 2016;46:672-80.

32. Schouten M, van't Veer C, Poulussen N, Meijers JC, Levi M, Esmon $\mathrm{CT}$, et al. The cytoprotective effects of endogenous activated protein $\mathrm{C}$ reduce activation of coagulation during murine pneumococcal pneumonia and sepsis. Thromb Res 2015;135:537-43.

Supplementary Material: The online version of this article offers supplementary material (https://doi.org/10.1515/cclm-2018-1350). 